\title{
Isolation of verotoxin-producing Escherichia coli associated with diarrhoea in Malaysia containing plasmids showing homology with biotinylated Shiga-like toxin DNA gene probes
}

\begin{abstract}
Three strains of verotoxin-producing Escherichia coli isolated from patients with haemorrhagic colitis harboured plasmids ranging in size from $2.7 \mathrm{~kb}$ to $91.2 \mathrm{~kb}$. Those plasmids ranging from $2.7 \mathrm{~kb}$ to $6.8 \mathrm{~kb}$ hybridized to Shiga-like toxin I and Shiga-like toxin II gene probes.
\end{abstract}

Keyword: Escherichia coli; Plasmids; Verotoxin 